\title{
The Influence of Smartphone Use on Academic Performance Among Indonesian University Students
}

\author{
MORISSAN \\ Universitas Mercu Buana, Jakarta, Indonesia
}

\begin{abstract}
University students use smartphones at every opportunity including in the lecture hall when they're attending courses. This study hypothesizes that there is a significant influence of smartphone use on academic performance. However, in assessing the influence, several other variables need to be considered such as gender, smoking habits, self-efficacy, academic efficacy, and romantic relationships. The sample of this study was students $(N=582)$ who were domiciled in Jakarta and surrounding areas (Jabodetabek). All analyses were carried out using SPSS through the following steps. First, the independent sample $t$-test and ANOVA were performed to examine the academic performance differences on three predictors: (1) sex, (2) smoking habit, and (3) romantic relationship. Second, hierarchical multiple regression was used to answer the research question whether or not there was a significant influence of smartphone use on academic performance by controlling the overall predictor variable? The results show that among smartphone user students, the female group showed better academic performance, as did students without romantic partners, and did not smoke. Calculation with multiple hierarchical regression shows that among all predictors examined, smoking behaviour is the most significant moderator variable in influencing academic performance $(\beta=-0.22$, $p<0.001)$, followed by cellphone use $(\beta=0.14, p<0.001)$.
\end{abstract}

Keywords: Academic performance, smartphone, students, university, Indonesia.

\section{INTRODUCTION}

Today, smartphones have become part of lifestyle, culture and an integral part of people's lives. Individuals seem increasingly difficult to break away from smartphones, especially the younger generation (Maryani et al., 2020). Among university students, smartphones are used at every opportunity. In each lecture hall, it is not difficult to see students who keep in touch with smartphones, both openly and secretly. Research showed that university students often used smartphones while they were attending classes even though there were rules that prohibit it (Tindell \& Bohlander, 2012).

On the other hand, since cellular technology grows rapidly, this device is also able to contribute to supporting student learning and improve academic performance. For example, students can get direct, easy access to many learning sources that previously could only be reached through computers connected to the Internet. Smartphones allow students to get information, documents (files) and interact with other students and their instructors online (Bull \& McCormick, 2012; Tao \& Yeh, 2013).

However, most students still view smartphones as a recreational and entertainment device. They used smartphones most often for friendship, social networking, surfing the Internet, watching videos, and playing games (Lepp et al., 2013, 2015; Nazilah et al., 2019). Students perceived smartphones usage more for leisure needs than education. Lekawael (2017) who studied the impact of smartphone and internet usage on English language learning among Indonesian primary to secondary school students found that most students spend much time to access the social network and games, and only a few students access 
internet for educational purposes. In short, students rather use smartphones for other things than education.

Han and Yi (2018) investigate the effects of smartphone use by South Korean college students on their perceived academic performance using a path analysis model. The study revealed positive and substantial relationships between students' self-efficacy and behavioural intention in using smartphones and academic performance.

Several other studies reveal that students often use smartphones in class when they study, and when they do homework (Jacobsen \& Forste, 2011; Junco \& Cotton, 2012). Kibona and Mgaya (2015) found that smartphones bring negative results on students' academic performance since they spent 5 -7 hours per day on social media without considering their academic works.

Another study showed that smartphone use could also encourage behaviour that was not conducive to academic success (Lepp et al., 2013). For example, university students tended to adopt a habit of using smartphones when they start feeling bored listening to lecturers' explanations or taking time to pause for a while using Twitter while they were doing homework (Lepp et al., 2013). The study also found that smartphone use was negatively related to physical fitness since it has disrupted physical activity and encourages lazy behaviour.

Several studies have attempted to measure the influence of smartphone use such as calls and SMS on academic performance. For example, Jacobsen and Forste (2011) identified a negative relationship between calling and sending messages with self-reported average scores (GPA) among university students in the United States. Similarly, another study found that calling and sending messages were positively correlated with the level of self-reported academic difficulties among a sample of Taiwanese university students (Hong et al., 2012).

Finally, Rosen et al. (2013) observed learning behaviour from a sample of junior, senior high school, and university students. Participants were observed for 15 minutes when they were working on an assignment (on-task) or not doing an assignment (off-task) that was recorded every minute. The results showed that participants usually become distracted on media such as Facebook, and also texting after less than 6 minutes of study time.

Excessive use befalls to those who spend a lot of time using their smartphones. The daily duration of smartphone use is one of the most significant indicators of excessive use. Park and Lee (2012) reported that those who use smartphone excessively prefer to use SNS. In addition, excessive use of SNS can have a negative impact on one's academic performance (Junco \& Cotton, 2012). In relation to the use of smartphones to play games, a study reports that the use of several game applications is a potential factor for someone to use the gadget excessively. Smartphone games can increase the risk of excessive use (Liu et al., 2016).

\section{Demographic factors}

Pratama and Scarlatos (2020) study the ownership and use of mobile devices among Indonesian middle and high school students. Based on a survey of 1,157 students, the findings show that both ownership and use of mobile devices varies significantly among students of different sex, age, location, and most importantly socioeconomic status. This study also shows some differences in duration and frequency of mobile apps use between different group of students. 
Gender, especially men, is a risk factor for the pathological Internet (Frangos et al., 2011). The results of the multivariate logistic regression revealed that men had a 50 per cent greater likelihood of Internet excessive use (odds ratio $(O R)=1.5,95 \%$ confidence interval $(\mathrm{Cl})=1.1,2.2$ ) compared to women (Lam et al., 2009). Women use the Internet mostly for social purposes and men do it to download programs, get information and visit pornographic sites (Tsitsika et al., 2009; Ybarra \& Mitchell, 2005). Other studies reveal that women are more dependent on smartphones than men, and women are more likely to be involved with a smartphone than men (Billieux et al., 2008; Walsh et al., 2011). Men are more likely to use their smartphones for functional purposes, such as work-related use, while women mainly use their smartphones to keep in touch with close people (Lemish \& Cohen, 2005; Rees and Noyes, 2007). Thus, it seems that men and women have different patterns of smartphone use.

\section{Self and Academic Efficacy}

A better understanding of the relationship between cell phone use and academic performance needs to include several additional established predictors into statistical models designed to assess this relationship. Several studies show that self-efficacy is one of the strongest predictors of academic performance (Pajares, 1996). In general, self-efficacy describes an individual's confidence in his ability to regulate and implement the behaviours needed for success; thus self-efficacy is a key mechanism in humans (Bandura, 1982). Research has identified self-efficacy as having a relationship with academic performance (Pajares, 1996). The power of self-efficacy in the academic field (academic self-efficacy) has a major influence on behaviour. Students with high academic efficacy make greater efforts to pursue academic targets, are more persistent in facing obstacles, and show greater interest in learning (Schunk, 1984, 1989). In addition, research shows that academic efficacy can mediate the effects of academic abilities (Pajares, 1996). As a result, academic efficacy is positively correlated with almost all measures of academic performance, including semester exam scores, cumulative GPA, homework, test scores, and writing assignments (Multon et al., 1991; Pajares, 1996).

\section{Relationship Status}

The literature that discusses the effect of romantic relationships on academic achievement is currently very limited, with most of the analysis relating to adolescents. One study of children and adolescents concluded that romantic relationships are related to low levels of academic achievement (Neemann et al., 1995). However, they found that the strength of this negative relationship disappeared when teens became older. Other studies report that romantic relationships can also function to improve academic performance if they have a smart and respectful academic partner (Furman \& Shaffer, 2003). A longitudinal study of more than 1,300 adolescents concluded that self-reported academic achievement depends on the value of their romantic partners (Giordano et al., 2008). Another longitudinal study of more than 400 young adults between the ages of 18 and 24 showed many similarities between romantic partners in their careers and educational goals (Manning et al., 2009). They also found that young adults consider their partners to have a positive influence on their academic goals rather than obstacles. 


\section{Research Questions \& Hypotheses}

Taking into account the previous research, a general hypothesis can be stated that cellphone use and academic performance have a negative relationship. The higher the level of cellphone uses the lower the academic performance. However, in assessing this relationship, there is a need to consider important control factors namely self-efficacy and academic efficacy. Thus, based on what has been described previously, this study raises the following research questions:

1) Is there a significant influence of smartphone use (calling, sending a text, playing games, social networking, browsing, use of various applications, etc.) on academic performance after controlling for several predictor variables such as gender, smoking behaviour, high school grades, self-efficacy, academic efficacy, and romantic relationships? Based on this research question, the research hypothesis can be formulated as follows:

$\mathrm{H}_{1}$ : There is a significant influence of smartphone use on academic performance after controlling for predictor variables of sex, smoking behaviour, high school grades, independent efficacy, academic efficacy, and romantic relationships.

2) How large is the prevalence of smartphone excessive use among students?

3) Are smartphone addiction groups more often having psychological and physical problems than normal groups?

\section{RESEARCH METHODS}

Taking into account previous studies, the present study hypothesizes that there is a significant influence of smartphone use and academic performance. However, in assessing the influence, there is a need to consider important statistical control variables such as gender, high school grades, self-efficacy, academic efficacy, romantic relationships, and smoking behaviour and can be described as shown in image 1 . The smoking behaviour variable is added because the prevalence of smoking among students is high in several cities (Putra et al., 2020).

In this study the total smartphone use was measured by the question: "How many hours on average do you use smartphones in one day?" With an 11-point rating scale, starting from scale 1; less than one hour per day, up to scale 11; more than 20 hours/day. Students' academic performance is measured by their academic achievement by asking the question: "What is your current GPA?" With eight answer choices ranging from less than 1.0, 1.0 - 1.4 to 3.5 - 4.0. In this case, students' academic achievement is measured using a 7-point ordinal scale based on their grade point average (GPA). The lowest scale is 1 for grade point or GPA of less than 1.0, and the highest scale is 7 for grade point/GPA between $3.5-4.0$. A sampling method of non-probability convenience sampling was used in taking the respondents.

The questionnaire was distributed online primarily through email and mobile. The sample of this study was students $(N=582)$ who were domiciled in Jabodetabek, an urban area or megacity surrounding the Indonesian capital city of Jakarta with a population of more than 28 million in 2010 (Kompas, 2011). This study chose Jabodetabek because the area has a heterogeneous population who come from various regions so that it can represent Indonesian urban students in general. 


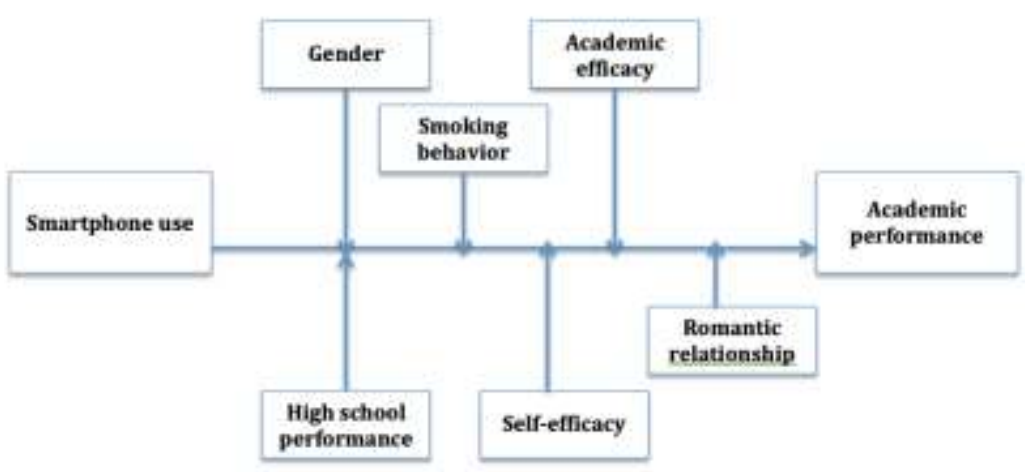

Figure 1: Relationship among variables

\section{Construct Measurement}

In terms of construct validity for smartphone excessive use, the statement on the questionnaire measures the level of satisfaction of life and relationships with others. The possibility of excessive use is measured by submitting three items $(\alpha=0.77)$ by using a 5 -point Likert scale such as: "My friend once said that I play too much smartphone"; "My family complains because I use my smartphone too often"; "My family and friends say that I am addicted to smartphones"; Thus, for each respondent, the lowest score being 3 which means the respondent is not excessive in using their gadget, the highest total score is 15 which indicates the possibility of the respondent using smartphone excessively.

Furthermore, respondents answered questions related to self-efficacy and academic efficacy. Self-efficacy aims to measure how well students believe they can use various independent learning strategies (Zimmerman et al., 1992, p. 668; Usher \& Pajares, 2008). In this study, the respondent's self-efficacy was measured by proposing eight statements, including: "I prepare a place to study at home to be free of interference."; "I can complete my college assignments on time"; "I keep learning even though there are other things that are more interesting to do". Respondents assessed each statement using a 5-point Likert scale, starting from strongly disagree (weight $=1$ ) to strongly agree (weight $=5$ ). Thus, for each respondent, the highest total score is 40 and the lowest is eight. Higher scores indicate greater self-efficacy. The value of Cronbach's alpha for the eight items is 0.75 .

Student academic efficacy was measured using eight items to determine students' confidence to achieve success in some subjects, for example: "During the exam, I can recall what I have learned"; "I quickly understand what I read"; "I can finish my college assignments well"; "I can achieve my goals in learning" (Gafoor, 2007). Respondents assessed each statement using a 5-point Likert scale, starting from strongly disagree (weight $=1$ ) to strongly agree (weight $=5$ ). Thus, for each respondent, the highest total score is 40 and the lowest is eight. Higher scores indicate greater academic efficacy. The value of Cronbach's alpha for the eight items is 0.77 . Both of these self-efficacy scales have consistently proven to be predictors of academic performance that can be relied upon in various contexts (Pajares, 1996). Likewise, the self and academic efficacy scale in this study with a sample of undergraduate students have shown strong internal consistency as well.

In the present study, high school academic performance is measured by one closedended question ("What are your academic achievements when you graduate high school?"), And one statement (I have good academic achievement in high school) with answer choices using a 5-point Likert scale. The total score of high school academic performance is obtained 
by summing up the weights of the two questions and statements so that the highest score is 10 and the lowest is 2.

\section{Data Analysis}

In this study, all analyses were carried out using SPSS version 25 through the following steps. First, the independent sample ANOVA and $t$-test were conducted to determine the difference in GPA between three predictor variables: 1) gender; 2) smoking habit and; 3) romantic relationship (having a romantic partner [boyfriend, husband, wife] or no partner). Second, hierarchical regression is used to answer the research question: Is there a significant influence of smartphone use on academic performance after controlling for predictor variables of sex, smoking behaviour, high school grades, independent efficacy, academic efficacy, and romantic relationships. To achieve this goal, hierarchical regression is carried out by proposing the analysis model as follows:

Academic performance $=$ Cellphone use $($ Block 1$)$

+ Gender, high school grades, smoking behaviour (Block 2)

+ Self-efficacy (Block 3)

+ Academic Efficacy (Block 4)

+ Romantic relationship (Block 5)

Smartphone use variable was included in the first block of this model. Furthermore, the other three variables that included gender, high school grades, and smoking behaviour were placed in the second block. Blocks 2 to 4 in this model are almost identical to the model developed by Zimmerman et al. (1992) and supported by others (for example, Caprara et al., 2011). This study added a romantic relationship to predict academic performance. Thus this model examines whether daily cellphone use relates to academic performance (GPA) and how much the other variables contribute to this relationship.

Finally, to further illustrate the influence of smartphone use on academic performance, the distribution of samples into three groups (tertile split) for smartphone use needs to be made. The sample was divided into three groups as follows: light, medium and heavy smartphone user groups. The ANOVA test was then used to compare the average value of smartphone use in the three groups.

In this study, as many as 650 people have tried to fill out questionnaires distributed online but as many as 44 people said 'no' to the question: "Are you currently registered as a student at one of the universities in Indonesia?" Thus, after removing respondents who did not meet the criteria, the number of eligible respondents to be analyzed was 606 . But before conducting descriptive and inferential statistics, an outlier check of continuous data (eg, age) must be performed to produce a normal distribution.

In terms of respondent age, the data obtained resulted in an average of 19.8 years, and a standard deviation of 1.51, and a range from the youngest of 17 to the oldest 25 years. Following the method of Rosen et al. (2013) and Lepp et al. (2015), the total measurement values that exceed three standard deviations are deleted from the data. Thus respondents aged over 25,133 or below 14,627 years were deleted from the data. This procedure resulted in 24 respondents being deleted and producing a final analysis sample of 582 students. The data that has been obtained from the questionnaire and was presented in the form of descriptive statistics, and then the data were analyzed by $t$-test and multiple hierarchical regression. 


\section{RESULTS AND DISCUSSION}

The process of collecting data resulted in a sample of 582 students consisting of 177 men (30.4\%) and 405 women (69.6\%). Most of the 521 students (89.6\%) claimed they were not smokers, while the remaining 61 people (10.4\%) were smokers. Respondents said that the main goal of using a cellphone was to "communicate with others" (29.8\%), followed by "accessing the latest information" (26.1\%), "seeking pleasure" (16.7\%), "reduce stress "(16.7\%) and "spending time "(4.3\%) while the remaining $6.4 \%$ includes various other reasons.

The most frequently accessed websites or content by respondents when using cellphones were related to social media (67.2\%), games (9.4\%), music (7.4\%), movies (5.4\%), and learning (4.7\%) while the remaining $5.9 \%$ accessed various other content. The most frequently accessed social media when using mobile phones is Instagram (77.9\%), WhatsApp (5.8\%), Twitter (4.3\%), Line (3.6\%), Facebook (2.7\%), and YouTube (2.6\%) and other social media.

In the variable of academic performance, the indicator used is the cumulative grade point average (GPA) and using an ordinal scale of 1 to 7 , data processing resulted in GPA of 4.44 (SD = $0.67, \mathrm{~N}=582$ ), or 2.53 in the score of GPA 1 - 4. The grouping of values produces the two biggest achievement index groups: Some $52.2 \%$ of respondents have an achievement index $3.5-4.0$ and $40.4 \%$ have an achievement index 3.0 - 3.4. Full data can be seen in Table 1. In terms of student academic performance when they were in high school, the majority of the sample amounting to 309 respondents (53.2\%) said that they had an average high school academic performance of 7.85 (SD = 1.13, $\mathrm{N}=582)$, or on a scale between 1-10 came into the category 'good enough' or 'good '.

Answering the question: "Do you currently have a romantic partner?" A total of 240 respondents (40.1\%) stated that they had a partner (boyfriend, husband, wife) and $358(60 \%)$ said that they did not have.

Table 1: Respondents' Achievement Index

\begin{tabular}{cccc}
\hline Scale & GPA & N & $\%$ \\
\hline 1 & $<1.0$ & 3 & 0,52 \\
2 & $1,0-1,4$ & 0 & 0,00 \\
3 & $1,5-1,9$ & 2 & 0,34 \\
4 & $2,0-2,4$ & 2 & 0,34 \\
5 & $2,5-2,9$ & 36 & 6,19 \\
6 & $3,0-3,4$ & 235 & 40,38 \\
7 & $3,5-4,0$ & 304 & 52,23 \\
& Total & $\mathbf{5 8 2}$ & $\mathbf{1 0 0}$ \\
\hline
\end{tabular}

Cellphone use duration by respondents was measured using an 11-point rating scale, and the data obtained showed the cellphone use duration was relatively scattered, starting from the shortest, less than 1 hour per day (scale $=1, N=6$ or $1 \%$ ), to the longest, or more than 20 hours per day (scale $=11, \mathrm{~N}=12$ or $2 \%$ ). However, the average time of cellphone use is 4.96, which means $6.0-9.0$ hours per day $(S D=2.17, N=582)$. While the largest group is those who used cellphones between four to seven hours per day that amounted to 274 respondents (45.8\%). 
Some 504 respondents (84.3\%) belonged to normal users who used cellphones 2 - 12 hours/day, or those who were within one standard deviation $( \pm 1 \sigma)$ of the mean; those belonging to mobile users with a duration above normal (14-17 hours/day), or those in the region of two standard deviations $(1 \sigma-2 \sigma)$ amount to 76 respondents (12.71\%); those belonging to sub-normal cellphone users (using cellphones only 2-3 hours/day), who was in the region of $-1 \sigma$ to $-2 \sigma$ of the mean, amounted to 36 respondents $(12.71 \%)$. There were no respondents who used cellphones for less than one hour per day. Finally, some 24 respondents (4.0\%) used cellphone more than 17 hours/day, or those who were at $2 \sigma-3 \sigma$ of the mean. This last group could be categorized as those who experienced cellphone addiction.

The results of data processing of self-efficacy with the lowest score 8 and the highest 40 produced respondents with a minimum score 13 , and maximum 40 , and an average 30.89 ( $S D=3.35, N=582$ ). While the academic efficacy variable with the lowest score 8 and the highest 40 produced respondents with a minimum score 17, and maximum 40, with an average 30.74 ( $S D=3.39, \mathrm{~N}=582$ ).

In the variable of smartphone excessive use that provides a score range of 3 to 15 , the data obtained from the respondents showed a minimum score 3 , and a maximum 14 , and the average 7.53 ( $S D=2.48, N=582$ ). If the level of cellphone excessive use is grouped according to standard deviation, or how far someone deviates from the mean in terms of cellphone use, those who had a score between 5.05 and $10.01(7.53 \pm 2.48)$ fall into the normal category (Mean $\pm 1 \sigma$ ), amounted to 443 respondents $(76.25 \%)$. There were 118 respondents $(20.4 \%)$ who showed cellphone use behaviour above normal, while 58 people (10\%) were below normal. Only 11 people (2\%) are in the region between two to three standard deviations ( $2 \sigma$

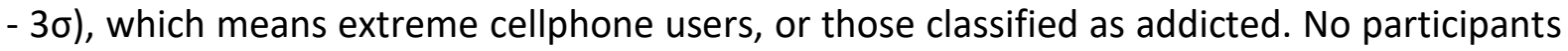
in the extreme low category $(-2 \sigma$ to $-3 \sigma)$.

Of the 582 respondents, most of them said they did not feel physical and psychological problem as a result of cellphone use (81.3\%) while the rest (18.7\%) found problems which included: headache, lethargy, aching neck and body, tingling hands, and insomnia. Psychological disorders include easily upset and anxious, depressed, angry, sensitive, the mood often changes to loneliness.

\section{Academic Performance Prediction}

In this study, data analysis was performed using a $t$-test and hierarchical multiple regression. An independent sample $t$-test was conducted to determine the effect of each independent variable individually on the dependent variable, academic performance. This calculation was made to compare differences in academic performance based on gender, high school grades, smoking behaviour, romantic relationships, self-efficacy, and academic efficacy. ANOVA test was conducted to determine the effect of each of the independent variables in synchrony on academic performance. Hierarchical multiple regression was used to find out: (1) how well the independent variables proposed in the model can predict academic performance; (2) Which independent variable is the best predictor for academic performance; (3) Are certain predictor variables can still predict results when the effects of other variables are controlled.

Before analyzing the data using the $t$-test, ANOVA and hierarchical multiple regression, several assumptions related to the three statistical instruments must be met. In the parametric statistical test, the first assumption is that the data analyzed must be interval or ratio scale. This research data comes from a questionnaire where each variable is measured by summing the weight of each statement given to produce interval data, thus assuming the type of data is met. In addition, this technique will not produce an extreme value (outlier) 
because the highest or lowest value has been determined, so the normality of the data can be maintained.

The second assumption is multicollinearity, which means there is no high correlation between the independent variables and the singularity assumption, which means that one independent variable, is not a combination of values from several other independent variables. Pearson correlation test showed that none of the relationships between variables produced a correlation value above 0.9 . The singularity assumption is also fulfilled because the variable data does not originate from time-series data or does not originate repetitive testing at various times.

The calculation results showed that there were significant differences in academic performance between female and male students where female students showed slightly better academic performance $(M=12.91, S D=1.49)$ compared to male students $(M=12.61$, $\mathrm{SD}=1.30$ ) conditions $t(574)=2.35, p<0.05$.

An independent sample $t$-test was conducted to compare academic performance between smoking students and non-smoking students. The calculation results showed that there were significant differences in academic performance between smoking and nonsmoking students. Non-smoking students showed slightly better academic performance $(\mathrm{M}=$ $12.94, S D=1.40)$ compared to smoking students $(M=11.68, S D=1.33)$ conditions $t(574)=$ $6.47, p<0.01$. In addition, an independent sample $t$-test was conducted to compare academic performance between students who had romantic partners and students who had no partners. The calculation showed that there are no significant differences in terms of academic performance between students who had no partner $(M=12.85, S D=1.50)$ and students who had a partner $(M=12.77, S D=1.34)$ condition $t(574)=0.71, p=0.48$.

A calculation using a two-way analysis of variance (ANOVA) was conducted to determine the effect of the three independent variables (gender, smoking behavior, and romantic relationship) on students' academic performance. Gender consists of men and women, smoking behaviour consists of two levels: smoking and not smoking, and romantic relationship consisting of two levels: having or not having a romantic partner. The results of the calculation showed that the three independent variables showed statistically significant results using a significance level of $p<0.05$.

The main effect in this model, gender, showed a ratio value $F(1,574)=4.56, p<0.05$, and this showed a significant difference between the academic performance of female students $(M=10.02, S D=1.31)$ and male students $(M=8.73, S D=1.03)$. This shows that female students have better academic performance. The second main effect in this model, smoking behaviour, showed a ratio value $F(1,574)=12.33, p<0.001$, this means that there are significant differences in academic performance between students who smoked $(\mathrm{M}=$ $8.81, S D=1.24)$ with students who did not smoke $(M=10.0, S D=1.27)$. This means that students who do not smoke have better academic performance than students who smoke. While the effect of romantic partners shows ratio value $F(1,574)=11.25, p<0.05$, this means that there are significant differences in academic performance between students who have romantic partners $(M=9.80, S D=1.28)$, with students who have no partners $(M=9.93, S D=$ 1.34). 
Table 2: Descriptive Statistics

\begin{tabular}{|c|c|c|c|c|c|}
\hline Variable & $N$ & Minimum & Maximum & Mean & $S D$ \\
\hline Age (years) & 582 & 17 & 25 & 19,80 & 1,75 \\
\hline GPA (Scale 1-7) & 582 & $1 / 1$ & $6 / 6$ & $5,43 / 4,44$ & $0,75 / 0,67$ \\
\hline High School Academic Performance (Scale 2-10) & 582 & 3 & 10 & 7,85 & 1,13 \\
\hline Duration of cellphone use (Scale 1 - 11) & 582 & 1 & 11 & 4,96 & 2,17 \\
\hline Self-efficacy (Scale 8 - 40) & 582 & 13 & 40 & 30,89 & 3,35 \\
\hline Academic Efficacy (Scale 8 - 40) & 582 & 17 & 40 & 30,74 & 3,39 \\
\hline Mobile addiction rate (Scale 3-15) & 582 & 3 & 15 & 7,53 & 2,48 \\
\hline Variable & Frequency & $\%$ & & & \\
\hline \multicolumn{6}{|l|}{ Gender } \\
\hline Man & 177,00 & 30,40 & & & \\
\hline Woman & 405,00 & 69,60 & & & \\
\hline \multicolumn{6}{|l|}{ Romantic couple } \\
\hline Have & 235,00 & 40,10 & & & \\
\hline Do not have & 347,00 & 59,90 & & & \\
\hline Smoking/No smoke & $46 / 536$ & $10,4 / 89,6$ & & & \\
\hline
\end{tabular}


Tabel 3: Correlational statistic of continuous variables $(N=582)$

\begin{tabular}{|c|c|c|c|c|c|c|c|}
\hline Variable & Age & GPA & $\begin{array}{l}\text { High school } \\
\text { performance }\end{array}$ & $\begin{array}{l}\text { Duration of } \\
\text { Cellphone use }\end{array}$ & $\begin{array}{c}\text { Self- } \\
\text { efficacy }\end{array}$ & $\begin{array}{c}\text { Academic } \\
\text { efficacy }\end{array}$ & $\begin{array}{c}\text { Smartphone } \\
\text { addiction }\end{array}$ \\
\hline Age & 1 & & & & & & \\
\hline GPA & .032 & 1 & & & & & \\
\hline \multicolumn{8}{|l|}{ High school } \\
\hline \multicolumn{8}{|l|}{ Duration of cellphone } \\
\hline use & .067 & $.158^{* *}$ & -.049 & 1 & & & \\
\hline Self-efficacy & .018 & .078 & $.357^{* *}$ & $-.193 * *$ & 1 & & \\
\hline Academic Efficacy & .047 & $.152^{* *}$ & $.356^{* *}$ & -.057 & $.720 * *$ & 1 & \\
\hline \multicolumn{8}{|l|}{ Smartphone } \\
\hline addiction & -.012 & -.010 & .003 & .065 & -.060 & -.011 & 1 \\
\hline Means & 19.78 & 9.87 & 7.85 & 4.95 & 30.89 & 30.74 & 7.53 \\
\hline Standard Deviations & 1.51 & 1.32 & 1.13 & 2.17 & 3.35 & 3.39 & 2.47 \\
\hline Range & $17-25$ & $3.0-11.0$ & $3.0-10.0$ & $1.0-11.0$ & $13.0-40.0$ & $17.0-40.0$ & $3.0-14.0$ \\
\hline Cronbach's Alpha & & & & & 0.75 & 0.77 & 0.77 \\
\hline
\end{tabular}

* Correlation is significant at the 0.05 level (2-tailed).

** Correlation is significant at the 0.01 level (2-tailed). 
Data shows that students who do not have a romantic partner have better performance than students who have a partner. In the further data analysis stage, the calculation is then used hierarchical multiple regression which aims to find out how well the independent variable (cellphone use) can predict academic performance if in the relationship other variables are placed including gender, high school grades, smoking behaviour, selfefficacy, academic efficacy, and romantic relationships. In this case, which combination of independent and dependent variables can be the best predictor of academic performance, and whether certain predictor variables can still predict results when the effects of other variables are controlled?

Calculation with multiple hierarchical regression was performed by incorporating independent variables into the relationship in the order determined by the researcher based on theoretical reasoning and previously published research. Hierarchical multiple regression was implemented to investigate the use of mobile phones to predict students' academic performance by taking into account gender, smoking behaviour, high school performance, self-efficacy, and academic efficacy. In this case, the independent variables were integrated into blocks. In the first block, smartphone use would be calculated. In the second block: gender, high school grades, and smoking behaviour were admitted into the calculation. Next, self-efficacy was included (Block 3), academic efficacy (Block 4), and finally the romantic relationship (Block 5). Each independent variable was reviewed based on the contribution delivered to the dependent variable after the independent variable was previously controlled. The relative contribution of each block, and then all models were reviewed.

The initial analysis was carried out to ensure that there were no violations of hierarchical multiple regression assumptions of normality and linearity. In addition, correlations between the predictor variables incorporated in this study were examined and presented (See Table 3), and all showed correlations ranging from $r=-0.010, p=0.04$ and $r=$ $0.72, p<0.05$. This shows that multicollinearity cannot be a problem because there are no $r$ values greater than 0.8 or 0.9 (see Tabachnick and Fidell, 2007). In addition, the threepredictor variables (high school grades, smartphone use, and academic efficacy) correlated significantly with the dependent variable, so that it could be applied for hierarchical regression checks.

In the first step of the calculation using hierarchical multiple regression, data on the intensity of cellphone use, which is an independent variable, is entered into the first block, and this model is statistically significant $F(1,574)=15.12 ; p<0.01$, and this first model contributes $2.5 \%$ to the variance in academic performance $(R 2=0.025)$. In the second step, three predictor variables were included in the second block: high school grades, smoking behaviour and gender. This second model is statistically significant $F(4,574)=17.1 ; p<0.001$, and explains $10.3 \%$ of the variance in student academic performance. This means an increase ( $R^{2}$ Change) of $7.9 \%$ from the previous model in the first block. This also shows that high school grades, smoking behaviour, and gender are moderator variables.

After the inclusion of self-efficacy in block three, the total variance explained by the model was $11.0 \%$, or increased by $0.6 \%$ from the previous model $F(5,574)=14.57 ; p<0.001)$. The entry of academic efficacy in the fourth block explained an additional $0.9 \%$ of the academic performance variant to become $11.8 \%$, after controlling high school performance, smoking behaviour, gender and self-efficacy $\left(R^{2}\right.$ Change $\left.=0.009 ; \mathrm{F}(6,591)=13.21 ; p<0.001\right)$. In the last or 5th block, the inclusion of romantic relationship variable shows that the model is statistically significant $F(7,574)=11.68 ; p<0.01$. In this fifth model smoking behaviour 
showed the highest unstandardized Beta value $(\beta=-0.22, p<0.001)$, followed by cellphone use $(\beta=0.14, p<0.001)$. Thus, smoking behavior is the most significant moderator variable in academic performance.

\begin{tabular}{|c|c|c|c|c|c|c|c|}
\hline & $R$ & $R^{2}$ & $\begin{array}{c}R^{2} \\
\text { Change }\end{array}$ & $B$ & $S E$ & B & $t$ \\
\hline Block 1 & .158 & $.026 * * *$ & & & & & \\
\hline \multicolumn{8}{|l|}{ Cellphone } \\
\hline use & & & & .097 & .026 & .158 & 3,88 \\
\hline Block 2 & .321 & $.102 * * *$ & $.078 * * *$ & & & & \\
\hline \multicolumn{8}{|l|}{ Cellphone } \\
\hline use & & & & .083 & .023 & $.133^{* *}$ & 3.421 \\
\hline Gender & & & & -.166 & .122 & -.058 & -1.359 \\
\hline \multicolumn{8}{|l|}{ High school } \\
\hline grades & & & & .086 & .046 & .073 & 1.874 \\
\hline Smoking behaviour & & & & -1.036 & .182 & $-.238 * * *$ & -5.604 \\
\hline Block 3 & .332 & $.112^{*}$ & $.006 *$ & & & & \\
\hline \multicolumn{8}{|l|}{ Cellphone } \\
\hline use & & & & .091 & .024 & $.149 * * *$ & 3.744 \\
\hline Gender & & & & -.186 & .122 & -.065 & -1.521 \\
\hline \multicolumn{8}{|l|}{ High school } \\
\hline grades & & & & .050 & .049 & .043 & 1.027 \\
\hline Smoking behaviour & & & & -1.006 & .183 & $-.233 * * *$ & -5.504 \\
\hline Self-efficacy & & & & .034 & .017 & $.086^{*}$ & 2.032 \\
\hline Block 4 & .345 & $.117^{*}$ & $.009 *$ & & & & \\
\hline \multicolumn{8}{|l|}{ Cellphone } \\
\hline use & & & & .084 & .024 & $.138 * *$ & 3.457 \\
\hline Gender & & & & -.202 & .122 & -.071 & -1.657 \\
\hline \multicolumn{8}{|l|}{ High school } \\
\hline grades & & & & .032 & .049 & .027 & .651 \\
\hline Smoking behaviour & & & & -.959 & .183 & $-.222 * * *$ & -5.235 \\
\hline Self-efficacy & & & & -.004 & .023 & -.009 & -.154 \\
\hline \multicolumn{8}{|l|}{ Academic } \\
\hline efficacy & & & & .053 & .022 & $.137^{*}$ & 2.406 \\
\hline Block 5 & .348 & .122 & .003 & & & & \\
\hline \multicolumn{8}{|l|}{ Cellphone } \\
\hline use & & & & .085 & .024 & $.141 * * *$ & 3.537 \\
\hline Gender & & & & -.214 & .122 & -.075 & -1.755 \\
\hline \multicolumn{8}{|l|}{ High school } \\
\hline grades & & & & .037 & .048 & .031 & .733 \\
\hline Smoking behaviour & & & & -.940 & .183 & $-.218 * * *$ & -5.128 \\
\hline Self-efficacy & & & & -.002 & .023 & -.004 & -.071 \\
\hline \multicolumn{8}{|l|}{ Academic } \\
\hline efficacy & & & & .053 & .022 & $.137^{*}$ & 2.400 \\
\hline $\begin{array}{l}\text { Romantic } \\
\text { relationship }\end{array}$ & & & & -.170 & .104 & -.059 & -1.525 \\
\hline
\end{tabular}

Note: Statistic significance: ${ }^{*} p<.05 ;{ }^{* *} p<.01 ;{ }^{* *} p<.001$ 
The ANOVA table shows that the overall model (which includes all five variable blocks) is significant $F(7,574)=9.69, p<0.01$. However, in the Standardized Coefficient column, two variables, self-efficacy, and high school performance did not show a significant effect $(p>$ $0.05)$, while the other three variables showed a significant effect on academic performance, namely: $g e n d e r(\beta=-0.1, p<0.05)$, smoking behaviour $(\beta=-0.22, p<0.01)$ and academic efficacy $(\beta=0.20, p<0.05)$.

As with previous studies, the results of the present investigation indicate that smartphone use has a significant relationship with academic performance as the study by Jacobsen and Forste (2011) who identified a negative relationship between cellphone use and self-reported average grades among students in the United States. Likewise, Junco (2012a, 2012b) found a strong negative relationship between the time spent accessing Facebook via mobile phones and the students' cumulative GPA. The study by Junco and Cotton (2012) showed that cell phone use (multitasking) was significant and negatively related to GPA with controls including gender, and high school grades. But the present study showed a weak relationship but in a positive direction between cellphone use and student academic performance $(R=0.157)$. This positive relationship is probably since cellphones are often used to access subject matter or do class assignments asked by lecturers, but further research is needed to get confirmation regarding this matter. It is in line with a study by Chen and Tzeng (2010) who found that information retrieval activities among heavy users of the Internet were associated with better academic performance while playing games with lower levels of academic performance.

Based on previous research, several demographic factors have also been identified as correlating with academic performance. Gender is one factor but proved inconsistent because it is largely dependent on subjects (Walpole, 2003). The present study also shows that gender has a significant influence on the relationship between cellphone use and academic performance. In the present case, female cellphone user students showed better academic performance $(M=12.91, S D=1.49)$, compared to male mobile phone users $(M=12.61, S D=$ 1.30) condition $t(596)=2.35, p<0.05$.

In addition to gender, this study also found that high school grades and smoking behaviour had a significant influence on academic performance as previous studies showed that the strongest predictors of academic achievement in higher education were high school achievements often measured by high school test scores, and standardized test scores (Betts \& Morell, 1999; Camara \& Echternacht, 2000; Ting \& Robinson, 1998). In this study three predictor was included in the second block: high school grades, smoking behaviour and gender showed statistically significant results $F(4,593)=17.1 ; p<0.001$, and explains $10.3 \%$ of the variance in academic performance. These results are in line with previous studies that indicated gender and smoking habits influence student academic achievement (Peter \& Horn, 2005). Likewise, smoking has been linked to cellphone use and poor academic performance (DeBerard, Spielmans, \& Julka, 2004; Sánchez-Martínez \& Otero, 2009).

Smartphone use not only produces pleasure, and reduces stress but can also cause failure to control cellphone use level and it may incur consequences that are financially, physically, psychologically and socially harmful in one's life (Shaffer, 1996; van Deursen et al., 2015; Young, 1999). In line with previous research, this study also showed that as many as $18.7 \%$ of respondents felt a physical disorder, which included: headache, lethargy, aching body and neck, tingling hands, and insomnia. In addition, people who were addicted to smartphones showed more psychosocial and health problems, they showed preoccupation 
and excessive use of smartphones than those who used smartphones less than 4 hours per day (Alijomaa et al., 2016). In this study, psychological disorders include easily upset and anxious, depressed, angry, sensitive, the mood often changes to loneliness.

The present study also shows that self-efficacy is one of the strongest predictors of academic performance (Pajares, 1996). Previous studies showed that self-efficacy was often a predictor of academic performance that was better than other social-psychological variables (e.g., Klomegah, 2007; Paulsen \& Gentry, 1995; Pintrich \& Schunk, 2002). In line with previous research, this study revealed that self-efficacy was also significantly associated with academic performance even though it was not the strongest predictor. However, self-efficacy remains an important variable to consider when studying the relationship between potential distractors such as cellphones or other new media, and academic performance (LaRose \& Eastin, 2004; LaRose, Lin, \& Eastin, 2003; LaRose, Mastro, \& Eastin, 2001; Odaci, 2011).

As the findings of Neemann, Hubbard, and Masten (1995), which concluded that romantic relationships are related to low levels of academic achievement, the present study also shows the same indication. This study found that students who did not have a romantic relationship tended to show higher academic achievement than those who had a romantic relationship. The effect of romantic partners showed the ratio value $F(1.590)=11.25, p<0.05$, this means that there are significant differences in academic performance between students who have romantic partners $(M=9.80, S D=1.28)$, with students who have no partners $(M=$ $9.93, \mathrm{SD}=1.34)$. Data shows that students who do not have a romantic partner have better performance than students who have a partner.

Academic performance may be one of the most difficult variables to estimate in social science since there is no single predictor that can predict academic performance. The main difference between the present study compared to previous research is that this study tries to measure as many as possible potential variables as predictors of academic performance. Previous research limited itself to certain predictors considered important. However, this research considers all the predictors are important, and this is a novelty. It is difficult to determine which is more important, for example, between self-efficacy and romantic relationships as predictors of academic performance before taking measurements directly on the specific sample intended.

\section{CONCLUSION}

In conclusion, the present study results indicate that there is a significant influence of smartphone use on academic performance, and among smartphone user students, female group shows better academic performance, as well as those who do not have romantic partners and do not smoke. Calculation with multiple hierarchical regression shows that cumulatively, smoking behaviour is the most significant moderator in influencing academic performance in a negative direction $(\beta=-0.22, p<0.001)$, and followed by cellphone use $(\beta=$ $0.14, p<0.001)$. In addition, the prevalence of smartphone excessive use among students, measured based on the number of respondents categorized as extreme mobile users (using cellphones more than 17 hours/day), or those in the deviation region $2 \sigma-3 \sigma$, was 24 respondents (4.0\%). But of this number, only 12 people (2\%) belong to the excessive use category. As many as $18.7 \%$ of respondents felt a physical disorder as a result of excessive cellphone use, which included: dizziness, lethargy, aching body and neck, tingling hands, and 
insomnia. Psychological disorders include easily upset and anxious, depressed, angry, sensitive, the mood often changes to loneliness.

BIODATA

Morissan is an Associate Professor at Faculty of Communication, University of Mercu Buana, Indonesia. His research interests are mass media especially television, social media, politics, and religions. Email: morissan@mercubuana.ac.id; morissan@yahoo.com 


\section{REFERENCE}

Bandura, A. (1982). Self-efficacy mechanism in human agency. American Psychologist, 37 (2), 122-147.

Betts, J. R., \& Morell, D. (1999). The determinants of undergraduate grade point average: The relative importance of family background, high school resources, and peer group effects. Journal of Human Resources, 34(2), 268-293.

Billieux, J., Linden, M.., \& Rochat, L. (2008) The role of impulsivity in actual and problematic use of the mobile phone. Applied Cognitive Psychology, 22, 1195-1210.

Bull, P., \& McCormick, C. (2012). Mobile learning: Integrating text messaging into a community college pre-algebra course. International Journal on E-Learning, 11, 233-245.

Frangos, C., Frangos, C., \& Sotiropoulos, I. (2011) Problematic internet use among Greek university students: An ordinal logistic regression with risk factors' negative psychological beliefs, pornographic sites and online games. Cyberpsychology, Behavior, and Social Networking, 14, 51-58.

Furman, W., \& Shaffer, L. (2003). The role of romantic relationships in adolescent development. In P. Florsheim (Ed.), Adolescent romantic relations and sexual behavior: Theory, research, and practical implications (pp. 3-22). Mahwah, NJ: Erlbaum.

Gafoor, K. A. (2007). Academic self efficacy scale (Thesis PhD, University of Calicut).

Han, S., \& Yi, Y. J. (2019). How does the smartphone usage of college students affect academic performance?. Journal of Computer Assisted Learning, 35(1), 13-22. https://doi.org/10.1111/jcal.12306

Hong, F. Y., Chiu, S. I., \& Hong, D. H. (2012). A model of the relationship between psychological characteristics, mobile phone addiction and use of mobile phones by Taiwanese university female students. Computers in Human Behavior, 28, 2152-2159.

Jacobsen, W. C., \& Forste, R. (2011). The wired generation: Academic and social outcomes of electronic media use among university students. Cyberpsychology, Behavior, and Social Networking, 14, 275-280.

Jeong, S. H., Kim, H. J., \& Yum, J. Y. (2016) What type of content are smartphone users addicted to? SNS vs. games. Computers in Human Behavior, 54, 10-17.

Junco, R., \& Cotton, S. R. (2012). The relationship between multitasking and academic performance. Computers \& Education, 59, 505-514. Http://dx.doi.org/10.1016/j.compedu.2011.12.023

Kibona, L., \& Mgaya, G. (2015). Smartphones' effects on academic performance of higher learning students: A case of Ruaha Catholic University Iringa, Tanzania. Journal of Multidisciplinary Engineering Science and Technology, 2(4), 777-784. http://www.jmest.org/wp-content/uploads/JMESTN42350643.pdf

Lam, L. T., Peng, Z.-W., Mai, J.-C., \& Jing, J. (2009) Factors associated with internet addiction among adolescents. CyberPsychology and Behavior, 12(5), 551-555.

Lekawael, R. F. J. (2017). The impact of smartphone and internet usage on English language learning. English Review: Journal of English Education, 5(2), 255-262. https://doi.org/10.25134/erjee.v5i2.540

Lemish, D., \& Cohen, A. A. (2005) On the gendered nature of mobile phone culture in Israel. Sex Roles, 52, 511-521. 
Lepp, A., Barkley, J. E., Sanders, G. J., Rebold, M., \& Gates, P. (2013). The relationship between cell phone use, physical and sedentary activity, and cardiorespiratory fitness in a sample of U.S. college students. International Journal of Behavioral Nutrition and Physical Activity, 10, Article $79 . \quad$ Retrieved from http://www.ijbnpa.org/content/10/1/79

Lepp, A., Li, J., \& Barkley, J. (2015). Exploring the relationships between college students' cell phone use, personality and leisure. Computers in Human Behavior, 43, 210-219.

Lepp, A., Barkley, J. E., \& Karpinski, A. C. (2015). The relationship between cell phone use and academic performance in a sample of U.S. college students. SAGE Open, 5(1), 1-9. https://doi.org/10.1177/2158244015573169

Levine, L. E., Waite, B. M., \& Bowman, L. L. (2007). Electronic media use, reading, and academic distractibility in college youth. Cyber Psychology and Behavior, 10, 560-566.

Liu, C. H., Lin, S. H., Pan, Y. C., Lin, Y. H. (2016) Smartphone gaming and frequent use pattern associated with smartphone addiction. Medicine, 95(28), e4068.

Manning, W. D., Giordano, P. C., Longmore, M. A., \& Hocevar, A. (2009). Romantic relationships and academic/career trajectories in early adulthood. Bowling $\mathrm{Green}, \mathrm{OH}$ : The Center for Family and Demographic Research, Bowling Green University.

Maryani, E., Rahmawan, D., \& Karlinah, S (2020). The Implications of Social Media on Local Media Business: Case Studies in Palembang, Manado and Bandung. Jurnal Komunikasi: Malaysian Journal of Communication, 36(1), 317-333. https://doi.org/10.17576/JKMJC-2020-3601-18

Multon, K. D., Brown, S. D., \& Lent, R. W. (1991). Relation of self-efficacy beliefs to academic outcomes: A meta-analytic investigation. Journal of Counseling Psychology, 1, 30-38.

Nazilah Ahmad@Ahmad Arifin, Umi Asma' Mokhtar, Zaihosnita Hood, Sabrina Tiun, \& Dian Indrayani Jambari. (2019). Parental awareness on cyber threats using social media. Jurnal Komunikasi: Malaysian Journal of Communication, 35(2), 485-498.

Neemann, J., Hubbard, J., \& Masten, A. S. (1995). The changing importance of romantic relationship involvement to competence from late childhood to late adolescence. Development and Psychopathology, 7(4), 727-750.

Oulasvirta, A., Rattenbury, T., Ma, L., \& Raita, E. (2012) Habits make smartphone use more pervasive. Personal and Ubiquitous Computing, 161(1), 105-114.

Pajares, F. (1996). Self-efficacy in academic settings. Review of Educational Research, 66, 543578.

Park, N., \& Lee, H. (2012) Social implications of smartphone use: Korean college students' smartphone use and psycho-logical well-being. Journal of Behavioral Addictions, 4(2), 85-92.

Putra, H. S., Rosemary, R., Yanuar, D., \& Ahsan, A. (2020). The wffect of cigarette advertising on smoking behaviour of students in Banda Aceh City, Indonesia. Jurnal Komunikasi: Malaysian Journal of Communication, 36(2), 348-363. https://doi.org/10.17576/JKMJC-2020-3602-21

Rees, H., \& Noyes, J. M. (2007) Mobile telephones, computers, and the internet: Sex differences in adolescents' use and attitudes. CyberPsychology and Behavior, 10, 482484. 
Robbins, S. B., Lauver, K., Le, H., Davis, D., Langley, R., \& Carlstrom, A. (2004). Do psychosocial and study skill factors predict college outcomes? A meta-analysis. Psychological Bulletin, 130(2), 261.

Rosen, L. D., Whaling, K., Carrier, L. M., Cheever, N. A., \& Rokkum, J. (2013). The media and technology usage and attitudes scale: An empirical investigation. Computers in Human Behavior, 29(6), 2501-2511. Retrieved from http://www.ncbi.nlm.nih.gov/pubmed/25722534

Sanchez-Martinez, M., \& Otero, A. (2009). Factors associated with cell phone use in adolescents in the community of Madrid (Spain). Cyberpsychology and Behavior, 12(2), 131-137.

Schunk, D. H. (1984). The self-efficacy perspective on achievement behavior. Education Psychologist, 19, 119-218.

Schunk, D. H. (1989). Social cognitive theory and self-regulated learning. In B. J. Zimmerman \& D. H. Schunk (Eds.), Self-regulated learning and academic achievement: Theory, research and practice (pp. 83-110). New York, NY: Springer Verlag.

Tao, Y., \& Yeh, C. R. (2013). Transforming the personal response system to a cloud voting service. In S. Uesugi (Ed.), IT enabled services (pp. 139-156). Verlag, Austria: Springer.

Tindell, D. R., \& Bohlander, R. W. (2012). The use and abuse of cell phones and text messaging in the classroom: A survey of college students. College Teaching, 60, 1-9.

Ting, S.-M. R., \& Robinson, T. L. (1998). First-year academic success: A prediction combining cognitive and psychosocial variables for Caucasian and African American students. Journal of College Student Development, 39(6), 599-610.

Torrecillas, L. (2007) Mobile phone addiction in teenagers may cause severe psychological disorder. Medical Studies, 14, 11-13.

Tsitsika, A., Critselis, E., Kormas, G., Konstantoulaki, E., Constantopoulos, A., \& Kafetzis, D. (2009). Adolescent pornographic internet site use: A multivariate regression analysis of the predictive factors of use and psychosocial implications. CyberPsychology and Behavior, 12, 545-550.

Usher, E. L., \& Pajares, F. (2008). Self-efficacy for self-regulated learning a validation study. Educational and Psychological Measurement, 68(3), 443-463. https://doi.org/10.1177/0013164407308475

Walpole, M. (2003). Socioeconomic status and college: How SES affects college experiences and outcomes. The Review of Higher Education, 27(1), 45-73.

Walsh, S. P., White, K. M., Cox, S., \& Young, R. McD. (2011). Keeping in constant touch: The predictors of young Australians' mobile phone involvement. Computers in Human Behavior, 27, 333-342.

Ybarra, M., \& Mitchell, K. J. (2005) Exposure to internet pornography among children and adolescents: A national survey. CyberPsychology and Behavior, 8, 473-486. 